DEPARTMENT OF COMMERCE

BUREAU OF STANDARDS

George K. Burgess, Director

TECHNOLOGIC PAPERS OF THE BUREAU OF STANDARDS, No. 268

[Part of Vol. 18]

\title{
A STUDY OF SILK WASTE USED FOR CARTRIDGE-BAG CLOTH, WITH AN APPENDIX ON THE GENERAL CLASSIFICATION OF WASTE SILK
}

BY

F. R. McGOWAN, Physicist

CHARLES W. SCHOFFSTALL, Associate Physicist

A. A. MERCIER, Textile Assistant

Bureau of Standards

December 4, 1924

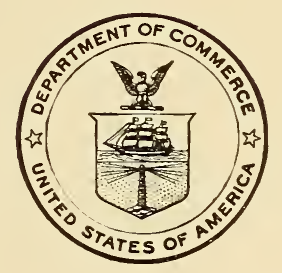

PRICE, 15 CENTS

\$1.25 PER VOLUME ON SUBSCRIPTION

Sold only by the Superintendent of Documents, Government Printing Office Washington, D. C.

WASHINGTON

GOVERNMENT PRINTING OFFICE

1924 



\title{
A STUDY OF SILK WASTE USED FOR CARTRIDGE- BAG CLOTH, WITH AN APPENDIX ON THE GEN- ERAL CLASSIFICATION OF WASTE SILK
}

\author{
By F. R. McGowan, Charles W. Schoffstall, and A. A. Mercier
}

\section{ABSTRACT}

A study was made of the waste silk used in the spun-silk industry in comparison with the waste silk purchased by the Government for the manufacture of cartridgebag cloth in order to find if the surplus of this cartridge-bag waste silk which remained on hand after the war was of use in connection with the normal textile requirements of the country. It was shown that this cartridge-bag waste silk was not suitable for use in the usual spun-silk processess of manufacture. Since this necessitated a continuance of the manufacture of this material on a system which combined the cotton and woolen systems of manufacture, as was the case during the war, a commercial use adaptable to the normal requirements of the country was extremely desirable. A fabric was woven using this material as a single yarn in the warp direction, unsized, with a wool yarn as the filling. Tests showed the resulting fabric to be suiting material well balanced in regard to wear. The general types of spun silk are given, and the system of grading is outlined in the appendix. Figures show the various grades of spun silk and the waste silk used for cartridge-bag cloth.

\section{CONTENTS}

I. General considerations.

I. Introduction ..................

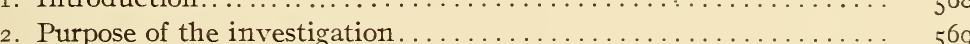

II. Silk waste used for cartridge-bag yarn ................... 570

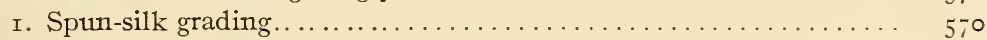

2. Grades of cartridge-bag waste silk. ................. 5 ;

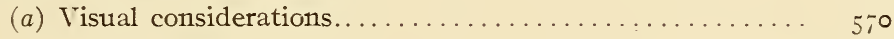

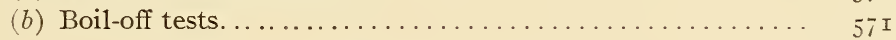

(I) For raw wastes........................ 573

(2) For wastes previously boiled off.......... 574

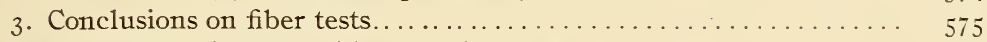

III. Uses for yarn made from cartridge-bag silk waste. . . . . . . . . . . 576

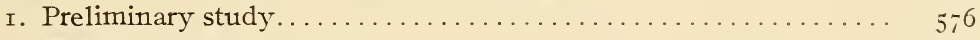

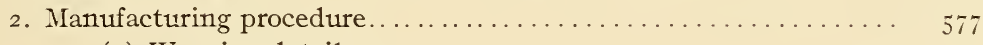

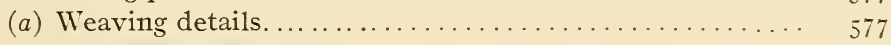

(b) Processes after weaving....................... $57^{8}$

3. Results of physical tests and observations on experimental fabric. . $\quad 578$

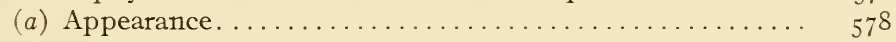

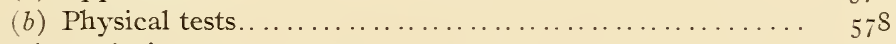

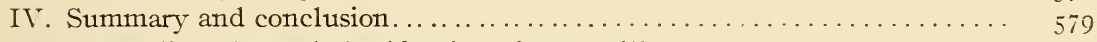

V. Appendix - General classification of waste silk . . . . . . . . . . $\ldots \ldots \ldots$

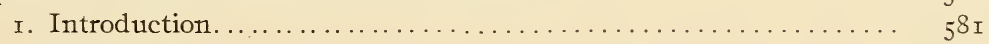

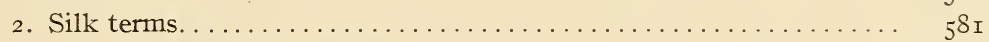

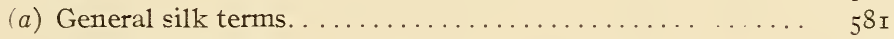

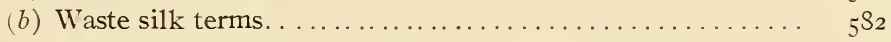

3. Wastes used in the spun-silk industry in the United States....... $5^{8} 3$ 


\section{GENERAL CONSIDERATIONS}

\section{INTRODUCTION}

At the end of the World War there were available large quantities of materials, which, produced primarily for war purposes, were of small use in connection with the normal textile requirements of the country. Among these materials was cartridge-bag silk, which the Government had on hand in three forms-raw, yarn, and finished fabric. Cartridge-bag cloth is entirely made of silk, so that it will burn with a minimum amount of ashes. It is made up in the form of bags or containers for powder used in all guns over 3 inches in diameter. In peace time the demand is small, and the cloth can be made from the by-products of the spun-silk industry, which are known commercially as "silk noils" or "exhaust silk noils."

When these by-products proved insufficient to meet the demand for cartridge-bag cloth, the European countries at war used spun silk for both the wrap and fillings of this material. This was very expensive, and, in addition, it was found that when the United States entered the war our relatively small spun-silk industry could not produce the quantities necessary to meet the war demand. A plan was then devised by which spun-silk yarn would be used in the warp direction of the cloth, and the woolen mills of the country would be utilized for spinning the filling from extremely low grades of waste silk which were unsuitable for use in the normal spun-silk industry. This waste silk had characteristics which made it suitable for use on this machinery for it could easily be broken up into short fibers and would thereby be made available for use on woolen cards. The waste silk used had not previously been imported in large quantities into the United States, and represented the lowest usable form of the byproducts resulting from the process of obtaining raw silk. This waste silk was taken over entirely by the Government, and with the spun-silk warp yarn obtained from the spun-silk mills was used to make the cartridge-bag cloth.

Since the reason for using silk in cartridge-bag cloth was that it should burn with a minimum ash residue, the ordinary considerations of luster and quality were unimportant. The cloth resulting had none of the characteristics of appearance possessed by the usual silk fabrics. It had no luster and had more the appearance of closely woven burlap than of silk. 
A tabulation of the results of tests on some of the cartridgebag cloths which were submitted for test during the war will show the general physical properties of this material. These results are shown in Table $\mathrm{I}$.

TABLE 1.-Tests of Cartridge-Bag Cloth

\begin{tabular}{|c|c|c|c|c|c|c|c|c|}
\hline \multirow{2}{*}{ Kind } & \multirow{2}{*}{ Grade } & \multirow{2}{*}{$\begin{array}{c}\text { Weight } \\
\text { per } \\
\text { square } \\
\text { yard }\end{array}$} & \multicolumn{2}{|c|}{$\begin{array}{l}\text { Breaking strength } \\
\text { strip method }\end{array}$} & \multicolumn{2}{|c|}{ Threads per inch } & \multirow{2}{*}{ Oil } & \multirow{2}{*}{ Gum } \\
\hline & & & Warp & Filling & Warp & Filling & & \\
\hline $\begin{array}{l}\text { Bag } \\
\text { Do } \\
\text { Do.. } \\
\text { Do }\end{array}$ & $\begin{array}{l}\text { B } \\
\text { C.-- } \\
\text { C.-. } \\
\text { D }_{--}\end{array}$ & $\begin{array}{r}\text { Ounces } \\
7.0 \\
7.3 \\
6.5 \\
6.3\end{array}$ & $\begin{array}{r}\text { Pounds } \\
84 \\
91 \\
64 \\
61\end{array}$ & $\begin{array}{r}\text { Pounds } \\
81 \\
84 \\
77 \\
65\end{array}$ & $\begin{array}{l}47 \\
49 \\
45 \\
39\end{array}$ & $\begin{array}{l}46 \\
54 \\
34 \\
40\end{array}$ & $\begin{array}{r}\text { Per cent } \\
1.58 \\
5.65 \\
3.16 \\
3.31\end{array}$ & $\begin{array}{r}\text { Per cent } \\
9.69 \\
7.07 \\
5.79 \\
7.62\end{array}$ \\
\hline $\begin{array}{r}\text { Do } \\
\text { Do } \\
\text { Do } \\
\text { Ignition } \\
\end{array}$ & $\begin{array}{l}\mathbf{D} \\
\mathbf{E}- \\
\mathbf{E} \\
\mathbf{B}\end{array}$ & $\begin{array}{l}5.7 \\
4.2 \\
4.3 \\
7.6\end{array}$ & $\begin{array}{l}58 \\
43 \\
39 \\
78\end{array}$ & $\begin{array}{l}52 \\
36 \\
37 \\
81\end{array}$ & $\begin{array}{l}45 \\
54 \\
27 \\
48\end{array}$ & $\begin{array}{l}42 \\
32 \\
29 \\
42\end{array}$ & $\begin{array}{l}1.05 \\
5.24 \\
3.76 \\
2.85\end{array}$ & $\begin{array}{l}4.09 \\
8.35 \\
4.23 \\
4.35\end{array}$ \\
\hline $\begin{array}{l}\text { Do } \\
\text { Do } \\
\text { Do }\end{array}$ & $\begin{array}{l}\text { C.- } \\
\text { D } \\
\mathbf{E}_{-}\end{array}$ & $\begin{array}{l}5.9 \\
5.3 \\
4.3\end{array}$ & $\begin{array}{l}85 \\
48 \\
37\end{array}$ & $\begin{array}{l}47 \\
36 \\
36\end{array}$ & $\begin{array}{l}45 \\
45 \\
28\end{array}$ & $\begin{array}{l}33 \\
36 \\
28\end{array}$ & $\begin{array}{l}3.08 \\
1.80 \\
3.12\end{array}$ & $\begin{array}{l}4.39 \\
6.18 \\
5.96\end{array}$ \\
\hline
\end{tabular}

The War Department attempted to find a market for the cartridge-bag cloth which remained on hand. After disposing of some by means of several style shows, where models exhibited various garments made from it, the large remaining amount was turned over to a commission house for disposal.

The difficulties encountered in adapting this war material to peace purposes definitely precluded the manufacture of the remaining waste silk and yarn, which was on hand, into cartridgebag cloth for sales purposes. The large amount on hand, however, made it expedient to find some use which would prevent the huge loss which would be incurred by its destruction. The waste-silk interests were reluctant to take over this raw material because, as stated, it had never been useful for normal purposes. The problem of finding new uses for it was accordingly submitted to the bureau for investigation.

\section{PURPOSE OF THE INVESTIGATION}

The purposes of the investigation were to find uses for the cartridge-bag waste silk and yarn which would make them of commercial value $(a)$ by ascertaining the suitability for use of these waste silks in the spun-silk industry and (b) by attempting to weave the yarn into a suitable fabric. 


\section{SILK WASTE USED FOR CARTRIDGE-BAG YARN}

\section{SPUN-SILK GRADING}

The waste silk usable on a commercial basis is graded according to the following points upon which a judgment of its desirability can be based, and fitted into a more or less definite classification: ${ }^{1}$ (I) Origin (country); (2) cultivation (a) wild, (b) domesticated; (3) cleanliness; (4) length of fiber; (5) amount of long fiber; (6) amount of tangled filaments on the end (flower); (7) per cent of yield from the boil off.

\section{GRADES OF CARTRIDGE-BAG WASTE SILK}

(a) VISUAL CONSIDERATIONS

The silk waste used for producing the filling direction of cartridge-bag cloth was much lower in grade than any which had been used before in the spun-silk industry of this country. Notwithstanding this, it had been assigned to the various spun-silk grades because there were no commercial grades which adequately described it.

In Figures I, 3, and 4 are shown various lots of the waste which was used in making cartridge-bag yarn. The extremely dirty and speckled condition of this waste, shown partly by the photographs, could only be realized by handling it. It was necessary to boil and reboil most of the waste before any further processing toward its manufacture into yarn could be accomplished. Figure I shows Canton steam waste raw and after it had been boiled twice. Figure 3 shows kibizzo neri, and Figure 4 shows frisonettes kompo in the raw and boiled-off stages.

By comparison with similar usual grades an idea of the poor quality of this material may be obtained. For instance, compare Figure I with Figure 2, both of which are graded as Canton steam waste. The difference in quality is unmistakable; the former, in addition to containing a number of worms, would require a great deal of processing before it could be manufactured.

To add to the difficulties experienced in handling these wastes, the grades were frequently mixed, for instance, in one lot marked "blaze," a regrading by qualified experts showed the following: Blaze woozie, blaze filature, blaze native extra, blaze native No. I, blaze filature Shaoshing, and blaze Japan combed No. I.

\footnotetext{
${ }^{1}$ See Appendix.
} 
(b) BOIL-OFF TESTS

To remove the gum or sericin from silk filature, it is necessary to boil the material for approximately one hour in a solution of

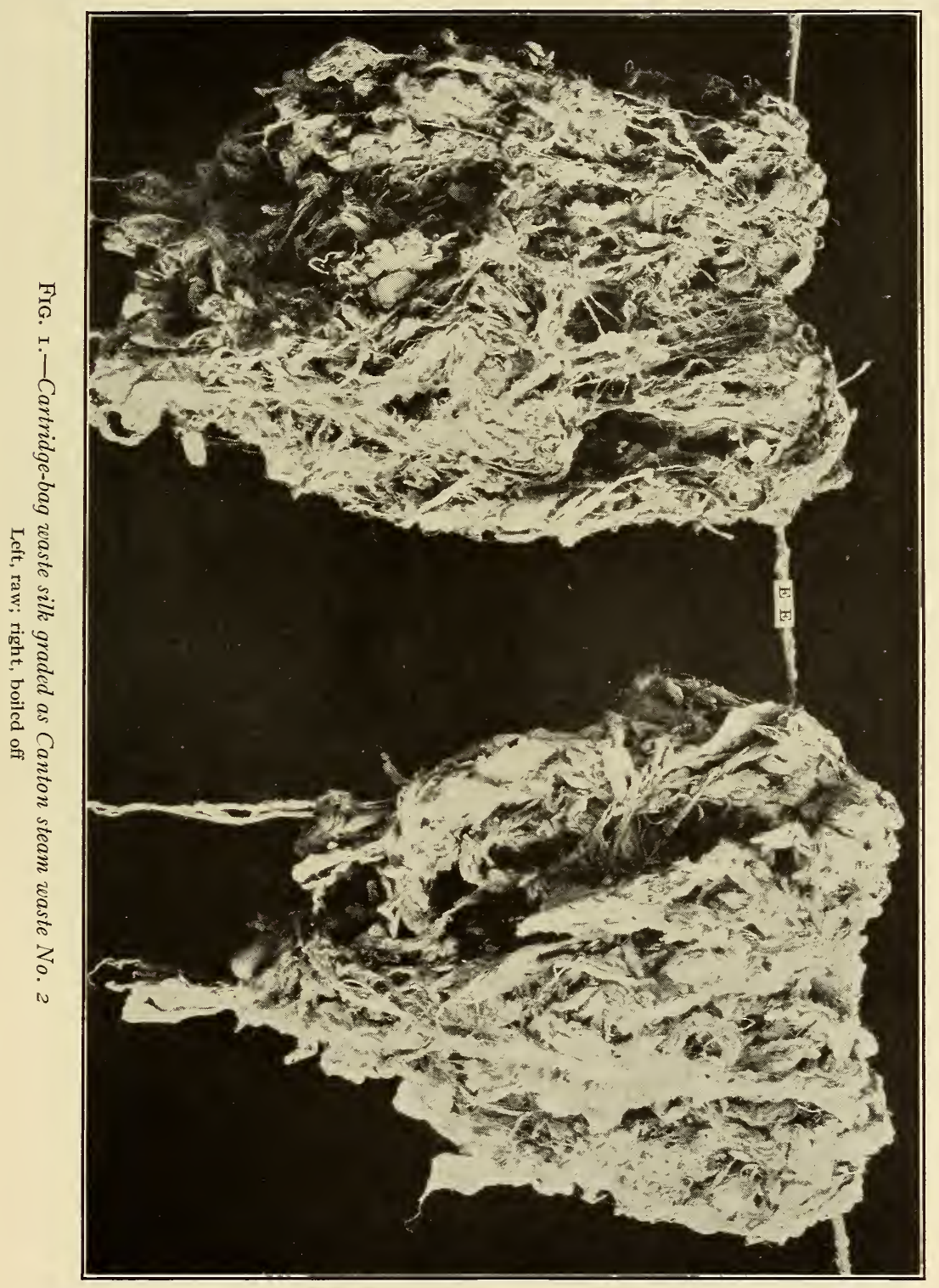

soda and neutral soap in water. This amount of gum varies, and, as indicated before, is one of the characteristics upon which the grade is based. In the waste used in the manufacture of cartridge cloth some large losses were noted in the boil off, several running 


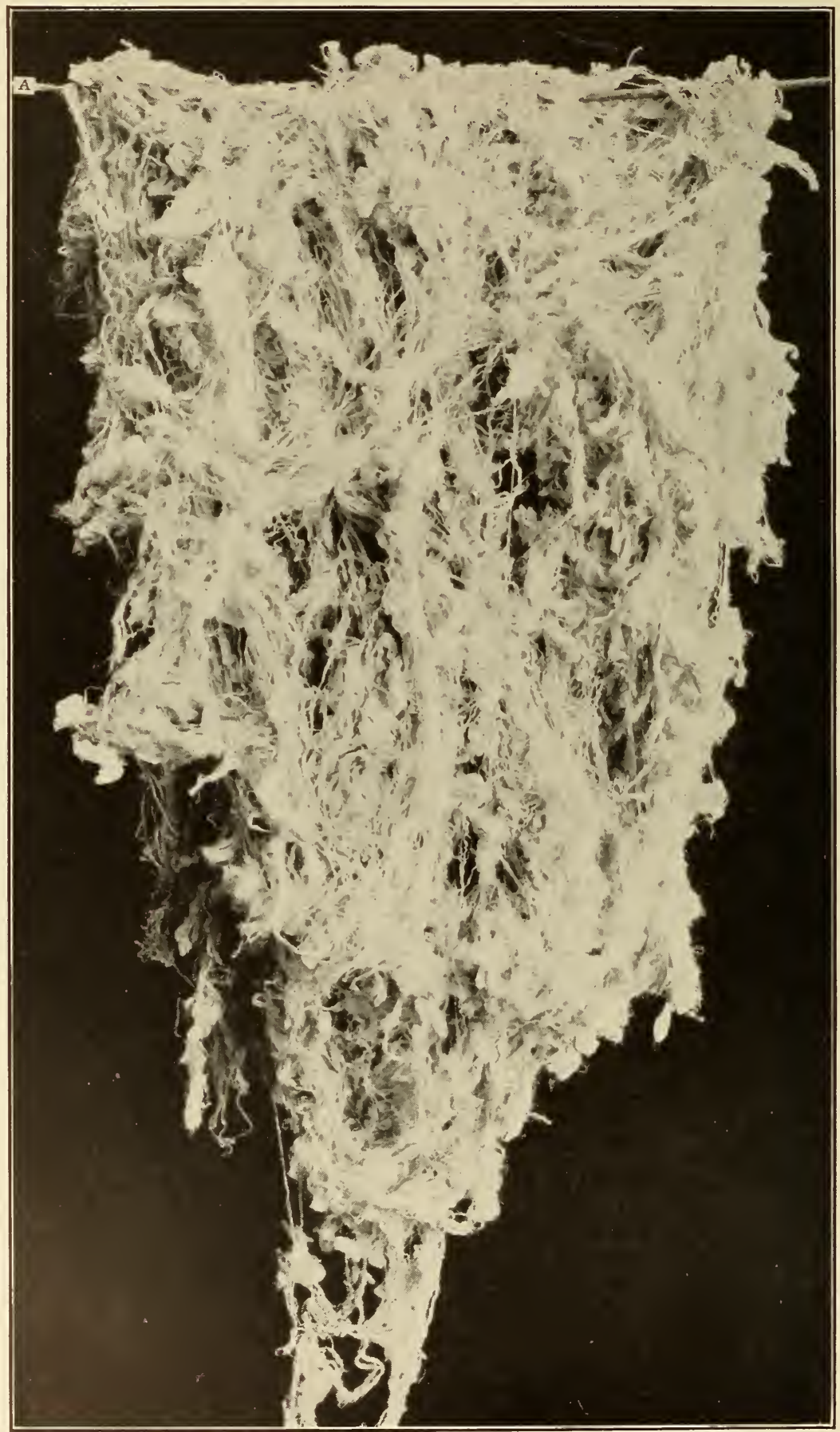

FIG. 2.-Highest grade Canton steam waste (raw) used in spun-silk manufacture 
as high as 60 per cent of the original weight. The usual losses in the boil off range from 25 to 40 per cent.

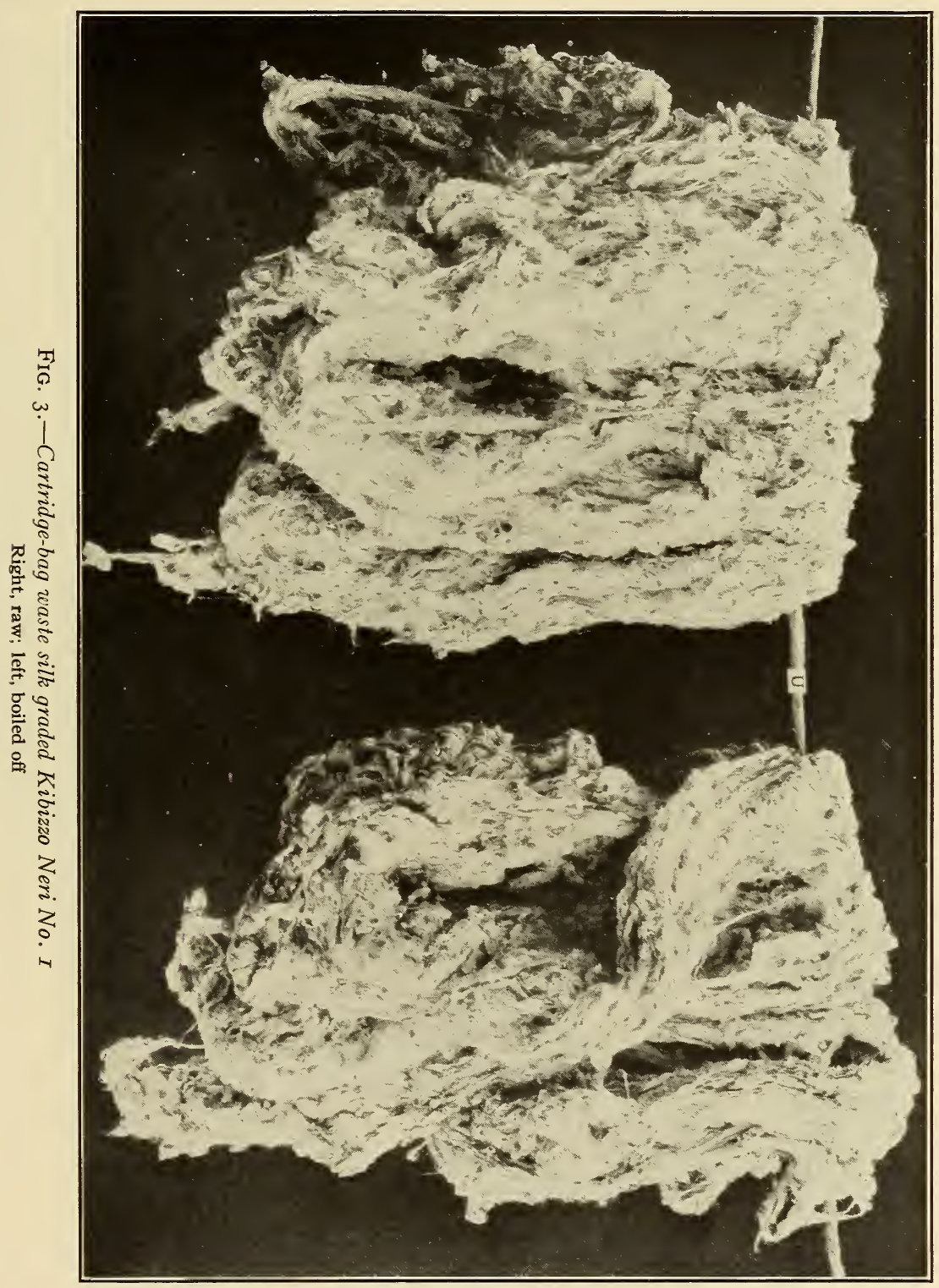

In the boiling-off process used to obtain the results shown in Tables 3 and 4 the following procedure was followed:

I. FOR RAW WASTES.-First boil, 20 pounds of sal soda and ro pounds of neutral soap. Boil one hour, extract. Second boil, $106653^{\circ}-24-2$ 
Io pounds of sal soda and $7 \frac{1}{2}$ pounds of neutral soap. Boil onehalf hour, wash thoroughly, extract, dry and shake.

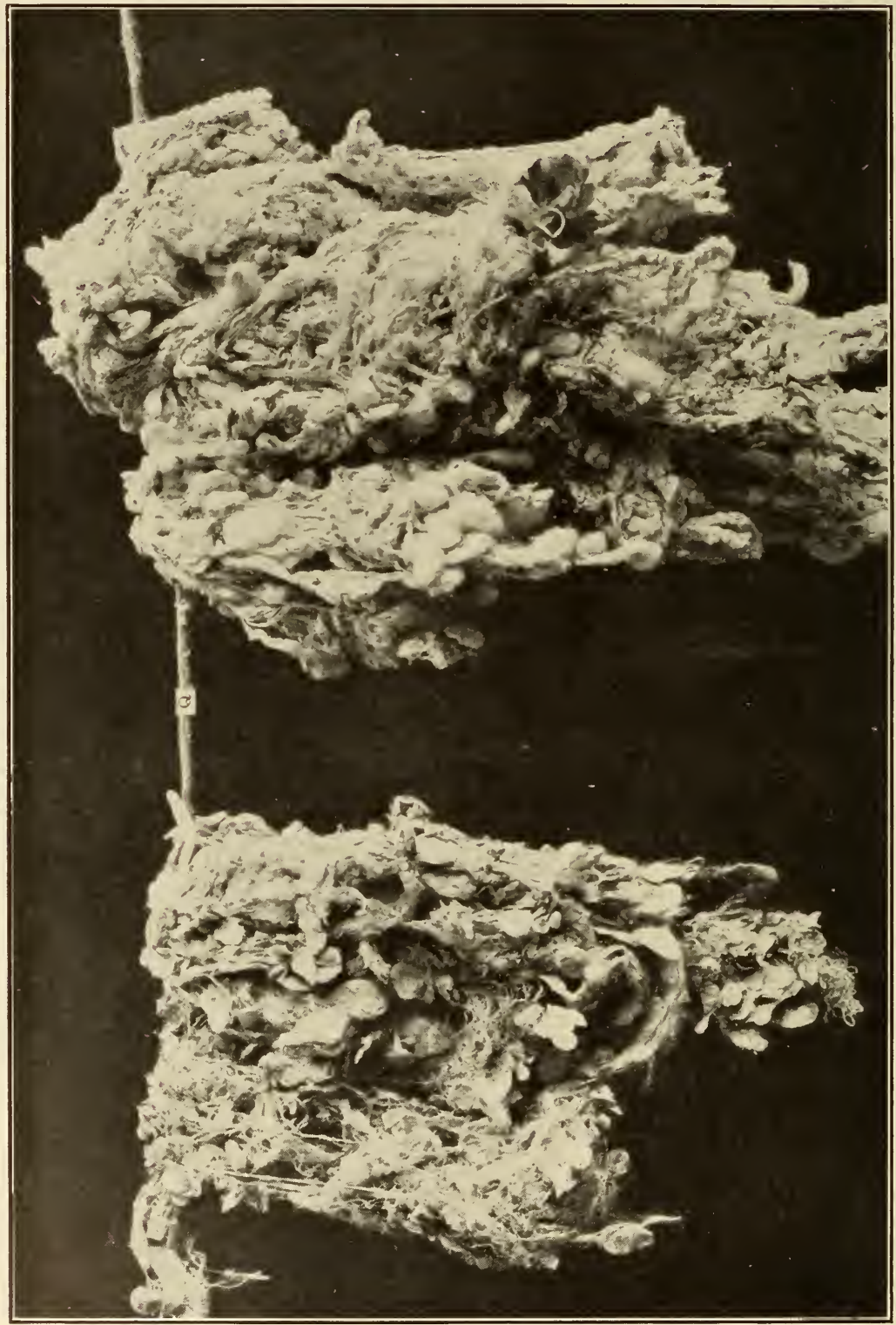

2. For Wastes Previously BoIled OFF.-Both boils similar to second boil under raw wastes.

A comparison of Tables 2, 3, and 4 shows the difference between the yields from the boiling process on the usual spun silks. Table 
2 shows the results from the customary commercial grades. Table 3 shows results of thorough boil-off tests on low grades in the raw states. Table 4 shows the results on samples of these same grades which had been marked and sold as "boiled-off" material. The percentage additional loss shown by a thorough boiling-off process was 15 to 28 per cent.

TABLE 2.- Percentages from Boil-off Tests on Commercial Grades of Waste Used for Spun Silk

\begin{tabular}{|c|c|c|c|}
\hline Grade & Yield & Grade & Yield \\
\hline $\begin{array}{l}\text { Canton steam waste No. } 1 \text { open extra } \\
\text { selected }\end{array}$ & $\begin{array}{l}\text { Per cent } \\
60.9 \\
59.0 \\
58.5 \\
56.3 \\
62.6\end{array}$ & Shanghai filatures. & $\begin{array}{l}\text { Per cent } \\
\left\{\begin{array}{r}72.6 \\
75.7 \\
70.3 \\
71.0 \\
68.5\end{array}\right.\end{array}$ \\
\hline Italian frison & $\left\{\begin{array}{l}70.4 \\
69.1 \\
67.1 \\
72.1 \\
66.1\end{array}\right.$ & Black Sea frisons. & $\left\{\begin{array}{l}63.0 \\
72.8 \\
65.5\end{array}\right.$ \\
\hline
\end{tabular}

TABLE 3.-Percentages from Boil-off Tests on Low Grades of Silk Used for Cartridge Bags

\begin{tabular}{|c|c|c|}
\hline Grade (as marked) & Yield & Loss \\
\hline $\begin{array}{l}\text { Szechuen frisonettes No. } 2 \\
\text { Kibizzo neri No. } 1 \\
\text { Frisonettes kompo } \\
\text { Canton steam waste No. } 2\end{array}$ & $\begin{array}{r}\text { Per cent } \\
39.0 \\
48.0 \\
45.0 \\
46.0\end{array}$ & $\begin{array}{r}\text { Per cent } \\
61.0 \\
52.0 \\
55.0 \\
54.0\end{array}$ \\
\hline
\end{tabular}

TABLE 4.--Percentages from Boil-off Tests on Samples Marked Boiled Off from Low Grades of Silk Used for Cartridge Bags

\begin{tabular}{l|r|r}
\hline Grade (as marked) & Yield & Loss \\
\hline & & Per cent \\
& Per cent \\
& & 20.5 \\
Szechuen frisonettes No. 2 (boiled off) & 85.0 & 15.0 \\
Kibizzo neri No. 1 (boiled off) & 76.0 & 24.0 \\
Frisonettes kompo (boiled off) & 71.6 & 28.4 \\
Canton steam waste No. 2 (boiled off)
\end{tabular}

\section{CONCLUSIONS ON FIBER TESTS}

Considerations of this cartridge-bag waste silk in comparison with the usual grades of spun silk resulted in the following conclusions:

I. Origin (country): Satisfactory.

2. Cultivation: Satisfactory. 
3. Cleanliness: Dirty condition would necessitate additional cleaning processes which would greatly increase the cost of preparation.

4. Length of fiber: Fibers were of very poor, uneven quality, and very irregular in length.

5. Amount of long fiber: A very small percentage was long fiber.

6. Amount of tangle filaments on the end: Tangled condition of fiber would not permit combing and drawing.

7. Per cent of yield from the boil off: Large losses were shown in the boil-off tests, several as high as 60 per cent of the original weight. The usual losses in the boil off ranged from 20 to 40 per cent.

From these considerations it was concluded that the cartridgebag cloth waste silk was unsuitable for the manufacture of spun silk on a commercial basis. The dirty condition and the percentage yield from the boil off would make profitable manufacture hazardous in competition with the usual spun-silk materials. In addition, the small amount of long fiber and its tangled condition would increase the manufacturing difficulties or render them insurmountable.

It was therefore decided that, since the material was unsuitable for manufacture according to the commercial spun-silk system, and since it had been utilized in making yarn for cartridge-bag cloth on the cotton and woolen systems, this practice should be continued provided a use for this yarn commercially could be found.

\section{USES FOR YARN MADE FROM CARTRIDGE-BAG SILK WASTE}

\section{PRELIMINARY STUDY}

In addition to the yarn which remained as surplus at the end of the war, the study of the waste silk showed that it was desirable to manufacture the large quantity of waste silk into similar yarn. This made the problem of finding a commercial use for this yarn more important than ever.

Test results on samples of the yarn which were submitted from the surplus supply showed that it was number $28 \mathrm{~s}$ yarn, according to the cotton numbering system. It had many slubs and 
irregularities on its surface, which raised some doubt in the minds of manufacturers as to whether the cloth could be woven from the yarn without difficulties which would make the cost prohibitive. A preliminary consideration suggested the possibility of using this yarn in conjunction with a woolen yarn to make ladies' suitings. By utilizing it in this connection as a single yarn in the warp direction its weaving characteristics could be observed and its commercial utility estimated.

\section{MANUFACTURING PROCEDURE}

For this study a sufficient number of bobbins were wound from the tubes of silk yarn submitted to make a 5oo-end warp. Three of these warps were combined to form a I,50O-end, 4OC-yarn warp beam. As it was desired to observe the performance of the yarn in an unsized condition, no slashing process was used.

The warp beam was then placed on a loom. The one used was a 3 o-harness, 4 by 4 box, two-warp worsted loom, with a $473 / 4$ inch reed, equipped with an American dobby, bat-wing picking motion, center stop motion, selvage motion, friction let-off, intermittent constant take-up, and inclined ring temples. It was run at 90 picks per minute. For this experiment four harnesses were used to give the largest possible range of ordinary weaves with least expenditure of labor in setting up. The ends were drawn through a No. 55 reed, three ends to a dent.

\section{(a) WEAVING DETAILS}

The details of the weaving were as follows:

Warp: Silk waste yarn size 28 s (cotton system).

Filling: Woolen yarn $4^{\mathrm{T} / 4}$ and $4^{\mathrm{T} / 2}$ run (woolen system), colors black, blue, brown, and green.

Reeded: 45 ends to the inch, reed No. 15 , three threads to the dent, I,500 ends, $33 \frac{\mathrm{T}}{3}$ inches wide in loom, and 40 picks per inch for filling.

Weaves used: Plain, basket and $\frac{2}{2}$ twill.

Some difficulty was encountered during the weaving process on account of the slubs and irregularities in the yarn which caused the warp yarns to catch and cling together. This could probably have been lessened considerably by sizing the warp yarn before weaving. 
In commercial practice this warp yarn would have been sized before weaving. In addition, it would probably have been woven 90 inches wide, using a number $22 \mathrm{I} / 2$ reed with two threads to the dent, the number of harnesses depending upon the weave. Finished commercial goods would, therefore, have measured 72 inches in width.

(b) PROCESSES AFTER WEAVING

I. Washed in cold water.

2. Washed in hot water $\left(98^{\circ} \mathrm{F}\right.$.) for $\mathrm{I}_{5}$ minutes.

3. Mixture of palm and neutral soap added to give suitable suds for 35 minutes.

4. Rinsed in cold water for 20 minutes or longer to remove any soap streaks.

5. Extracted.

6. Tentered and dried to 28 -inch width.

\section{RESULTS OF PHYSICAL TESTS AND OBSERVATIONS ON EXPERI- MENTAL FABRIC}

(a) APPEARANCE

The finished fabrics had a soft texture and presented a fulled surface. The white threads of the warp showed indistinctly and only a few of the slubs were evident; those showing, however, seemed to enhance the color of the filling yarns and improve the appearance generally.

\section{(b) PHYSICAL TESTS}

The results of the physical tests of the finished fabric were as follows:

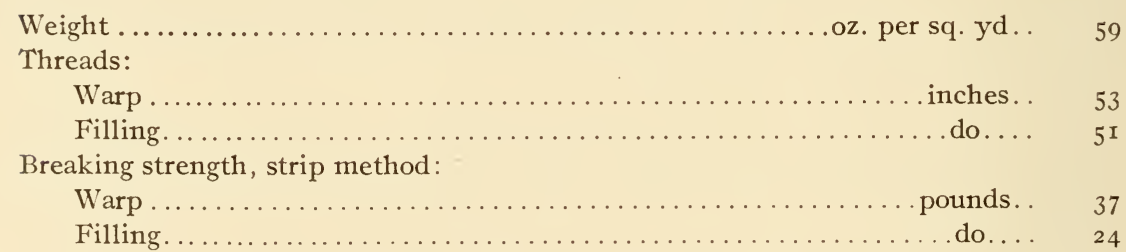

All tests were made after the sample had been conditioned for at least four hours at 65 per cent relative humidity at $70^{\circ} \mathrm{F}$.

The breaking-strength tests were made according to the strip method of test. The strength-test specimens were cut I $1 / 4$ by $\mathrm{I} 2$ inches and raveled to I inch, taking from each side approximately the same number of yarns. The machine was of the inclination 
balance type with a stretch measurement attachment. The maximum capacity of this machine was I5o pounds. The lower or pulling jaw traveled at the uniform rate of $\mathrm{I} 2$ inches per minute under no load. The distance between jaws was 6 inches at the start of test. Three tests were made in each direction.

This fabric shows balanced performance, which is a very desirable characteristic for wearing apparel. By a balanced fabric in relation to wear is meant that both warp and filling have the same rate of stretch at various loads up to those which are likely to be put into use. In these results this balanced condition holds true up to 22 pounds per inch, a load greater than that which is generally applied to fabrics of the dress or suiting-goods type in actual service. The stretch relation is shown in Figure 5.

\section{SUMMARY AND CONCLUSION}

The study of waste silk used in the spun-silk industry in comparison with the waste silk remaining on hand at the end of the war, which had been purchased by the Government for the manufacture of cartridge-bag cloth, showed that the latter was not suitable for manufacture by the usual spun-silk processes. This made it necessary to continue the manufacture of yarn from this waste on the cotton and woolen systems.

It was then shown that the cartridge-bag yarn could be woven successfully into materials which would have a commercial value. In weaving, the waste-silk yarn was used as a single yarn, unsized, for the warp and a woolen yarn was used for the filling. The weaving details could be varied as desired, for the feature brought out was that the yarn could be woven as a single yarn even when no sizing was used.

After this investigation had shown a method of utilizing this very low-grade silk waste, the Government was enabled to effect a satisfactory sale of all such material on hand.

By demonstrating the practicability of using waste so low in grade that it had never been found profitable previous to the demand created by the need for cartridge bags to import it into this country, this investigation has opened a new field for the manufacture of textiles from a comparatively inexpensive raw material. 


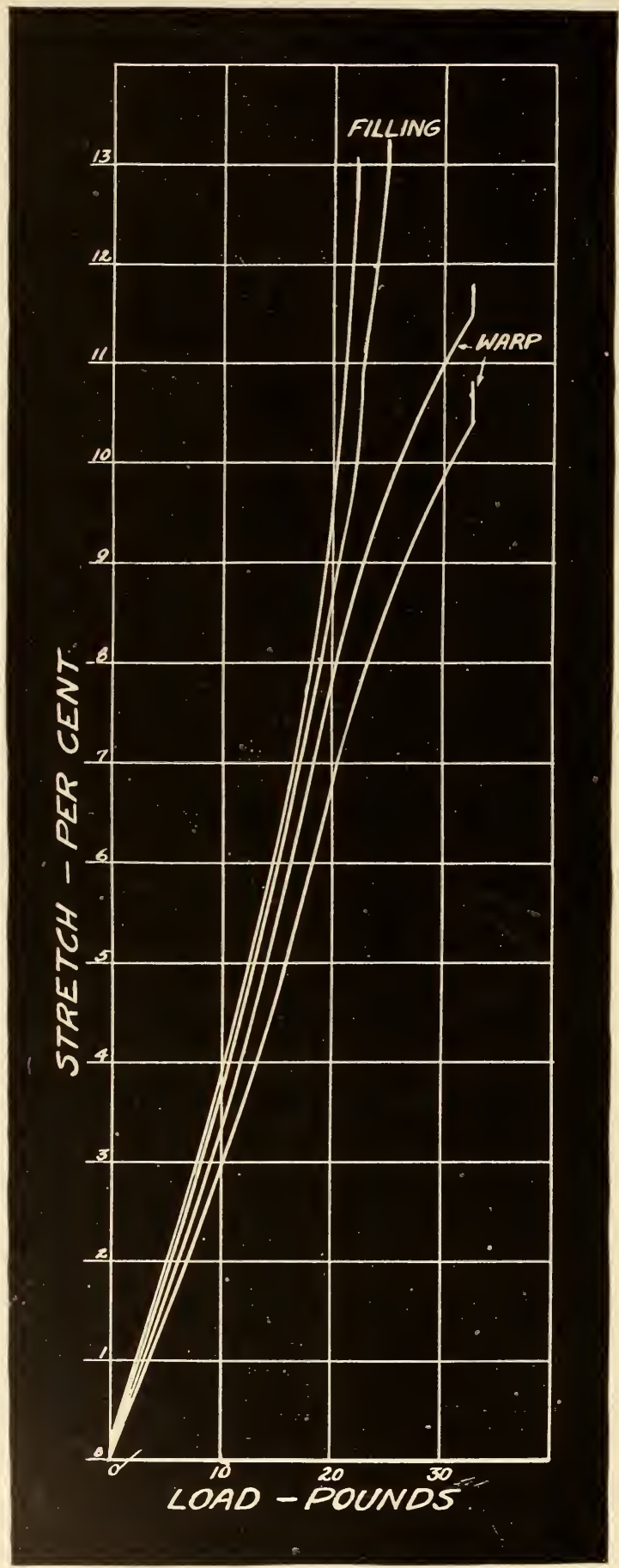

FIG. 5.-Load stretch curve on sample of experimental fabric, waste silk warp, wool filling Specimen dimensions I by ${ }_{2} 2$ inches 


\section{APPENDIX-GENERAL CLASSIFICATION OF WASTE SILK}

\section{INTRODUCTION}

During the course of this investigation it was found necessary to prepare a digest of terms used in the classification of waste silk. These are presented here as of specific interest in connection with the subject matter covered in this paper.

\section{SILK TERMS}

(a) GENERAL SILK TERMS

(I) Silk Fiber.-The silk fiber consists of a double filament (bave) of animal nature produced by the silkworm, possessing great luster, elasticity, and strength. In the cycle of life of the silkworm, the worm hatches from the egg; the worm when fully grown spins a cocoon around itself, changing in a few days into a chrysalis, which is transformed into a moth; the moth lays its eggs (about 300 to 400 , each the size of the head of a pin) and the cycle is complete. This cycle requires about two months.

(2) True Silk is a term applied to the fiber which, by killing the worm before it breaks through the cocoon, is obtained in a long continuous strand ranging from 300 to 700 yards in length. The silk emerges from the two small orifices on the head of the worm in the form of a double filament. Usually 2,500 to 3,000 cocoons will make a pound of raw silk. Only half the silk in a cocoon can be reeled; the remainder is waste.

(3) Thrown Silk indicates that several fibers as reeled from the cocoon have been twisted together. A single cocoon fiber is too fine to be used commercially, so three or more are generally reeled together. They adhere to each other on account of the gum or serecin with which they are covered. These are then twisted or "thrown" to avoid matting or entangling in the dyeing process. The size of yarn thus prepared depends on the number of cocoons reeled together. Since the cocoon fiber varies in size at different seasons of the year, this number varies for the same size (denier) of silk yarn. The most extensively used size in this country, $\mathrm{I}_{3} / \mathrm{I}_{5}$ deniers, is generally reeled from six or seven cocoons. One pound of $\mathrm{I}_{3} / \mathrm{I} 5$ deniers will measure about I8I miles. Thrown silks are known as singles, trams, or organzines.

(4) Singles, as the name implies, are single raw silk yarns twisted or not. When very hard twisted these yarns are used for chiffons, crêpes, and similar fabrics. 
(5) Tram is made by combining several singles. Tram is generally only very lightly twisted and is used for the filling direction. When hard twisted it is used in crêpes, chiffons, etc.

(6) ORGANZINE is made by twisting together two hard-twisted singles (sometimes more) in the opposite direction to the twist of the single. This is used for the warp direction.

\section{(b) WASTE SILK TERMS}

(I) Silk WASTE.-From all of the operations in preparing the true silk fiber there results some waste. Most of this waste is utilized in the waste-silk industry. It is classed as follows:

(A) Fibers which can not be used in the reeling process.- I. Blaze.-The first fibers produced by the silk worm when the cocoon is being made are known as blaze. They are fine in texture, weak, and wrapped loosely around the cocoon.

2. Imperfect cocoons which can not be reeled commercially.-Double cocoons: Cocoons which have not been properly constructed.

Feeble cocoons: Cocoons which have not been developed properly on account of sickness of the worm.

Pierced cocoons: Cocoons from which the chrysalis has emerged, causing a small hole. These usually result from breeding when the worm is permitted to emerge for reproduction purposes.

Piques and rates: Cocoons which have a hole eaten by moths or rats.

(B) By-products of reeling process of cocoons.-I. Frisons or knubs. - The fibers which are brushed from the cocoons until the thread which unwinds properly is found.

2. Bassinets and pelettes are partly reeled cocoons which. because the filament on the inner layers of the cocoon is fine and weak, break during the reeling process and drop to the bottom of the basin. Bassinets contain 20 to 45 per cent and pelettes contain $\mathrm{I} 2$ to 20 per cent of the original weight of silk on the cocoon.

3. Frisonettes or crapauds.-Small silk mills frequently combine frisons, bassinets, and pelettes under the name of frisonettes. The value of the lot depends on the proportion of each of these kinds present.

(C) Wastes produced in reeling, winding, throwing, and weaving of raw silk are called, variously, bourres, bourettes, gum waste, and winders' and throwsters' waste.--The specific names of the different kinds of waste vary in accordance with local terms used in the different producing countries. Some of these are shown in Table 5 . 
TABLE 5.-General Survey Showing the Terms Used for Silk Wastes Produced in the Principal World Markets ${ }^{1}$

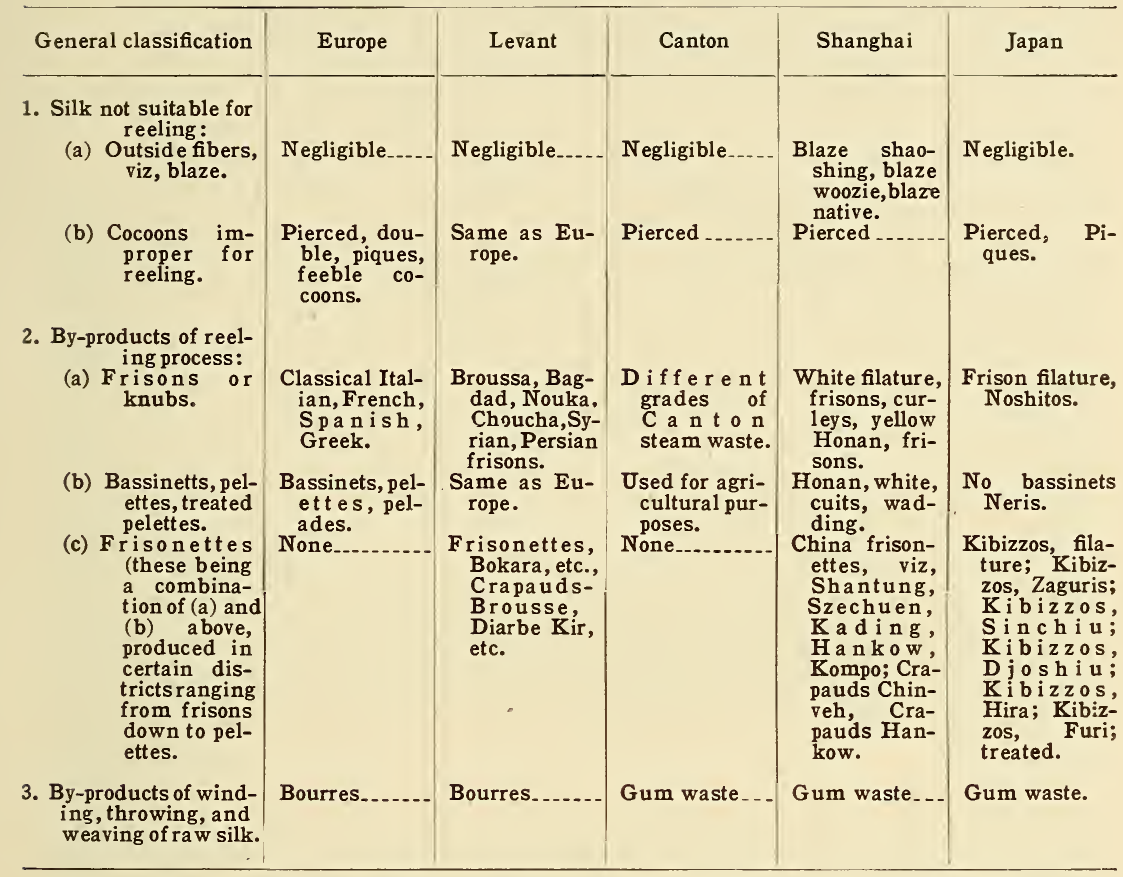

1 The term used by the United States, in connection with section 3 of this table, is "Domestic waste." NotE.-This table is not intended to give a complete list of all silk waste, but gives the principal representative sorts only.

\section{WASTES USED IN THE SPUN-SILK INDUSTRY IN THE UNITED STATES}

In the United States the silk waste is used in manufacturing spun-silk products. Selected waste fibers ranging from several inches to 5 feet are spun into a strand. The term "spun" is an accurate one, for the yarn is actually spun and not merely twisted as in the case of raw silk. The yarn number or yarn size of spun silk is based on 840 yards of No. I yarn equaling I pound, I,680 yards of No. 2 yarn equaling I pound, etc. The European term for "spun silk" is "schappe."

Of the above survey (Table 5), the only silk wastes which have been imported and commercially used in the United States for spun-silk manufacture are the following: Pierced cocoons from all producing countries and in some cases pique cocoons and double cocoons; highest grades of frisons from Europe (Italian, French, Spanish, and Greek frisons) and from the Levant (Bagdad, Nonka, Bronssa, and Syria) and similar kinds from Canton (Canton steam 

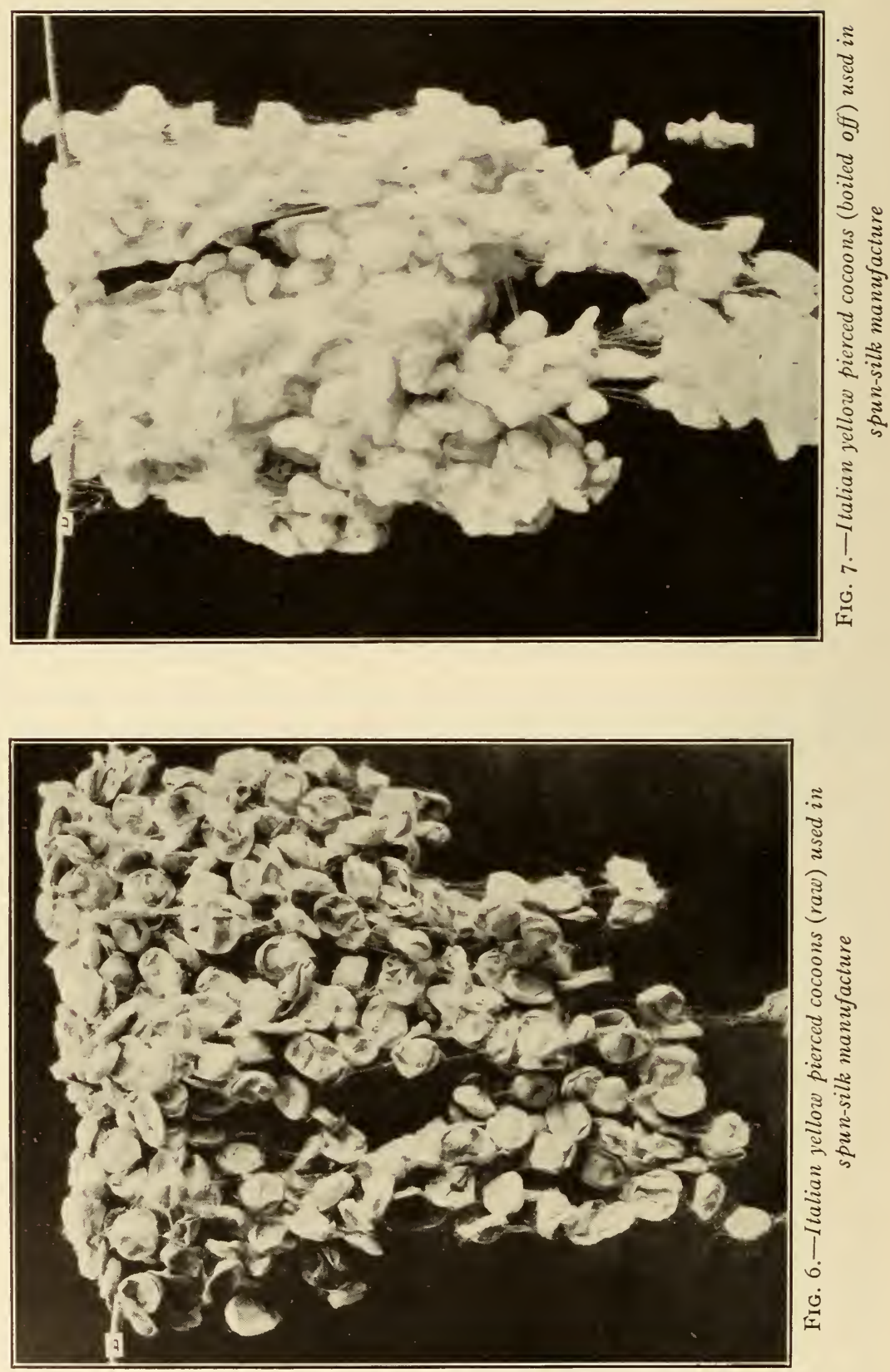
waste); from Shanghai and from Japan the highest grade of Japanese frisonette class, known as Kibizzo filature, which contain only a small portion of bassinetts and pelettes; and all silk waste produced in America in the winding, reeling, and throwing processes, known as domestic winders' and throwsters' waste.

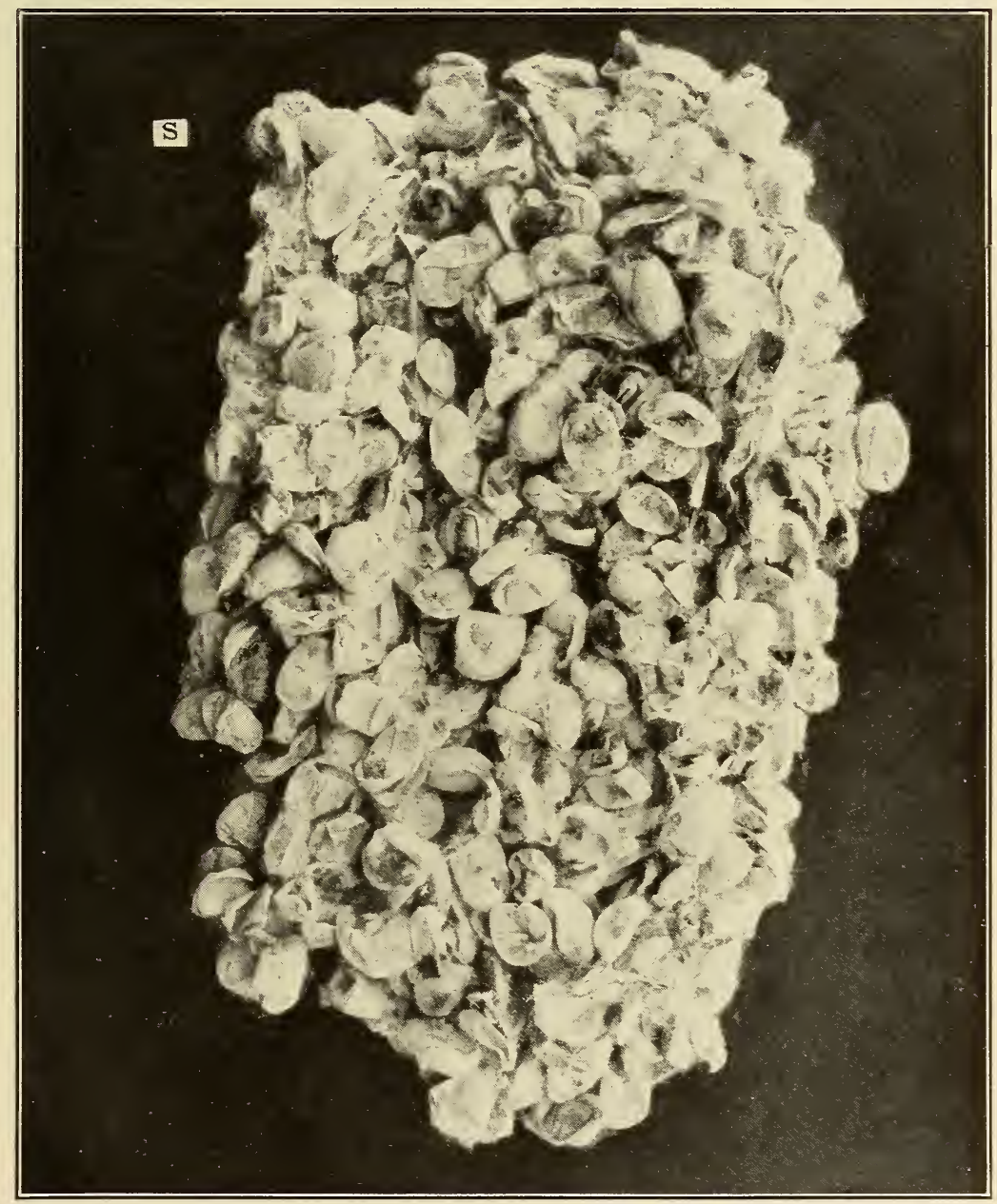

FIG. 8.-Pique cocoons (raw) used in spun-silk manufacture

Figures 6 to 8 show various kinds and states of silk waste which have a commercial value in the spun-silk industry. These wastes were not used to any extent for making filling yarn for cartridgebag cloth by the United States Government on account of their cost and insufficient quantity. Figures 6,7 , and 8 show piques and pierced cocoons which, because the worm has emerged, are 


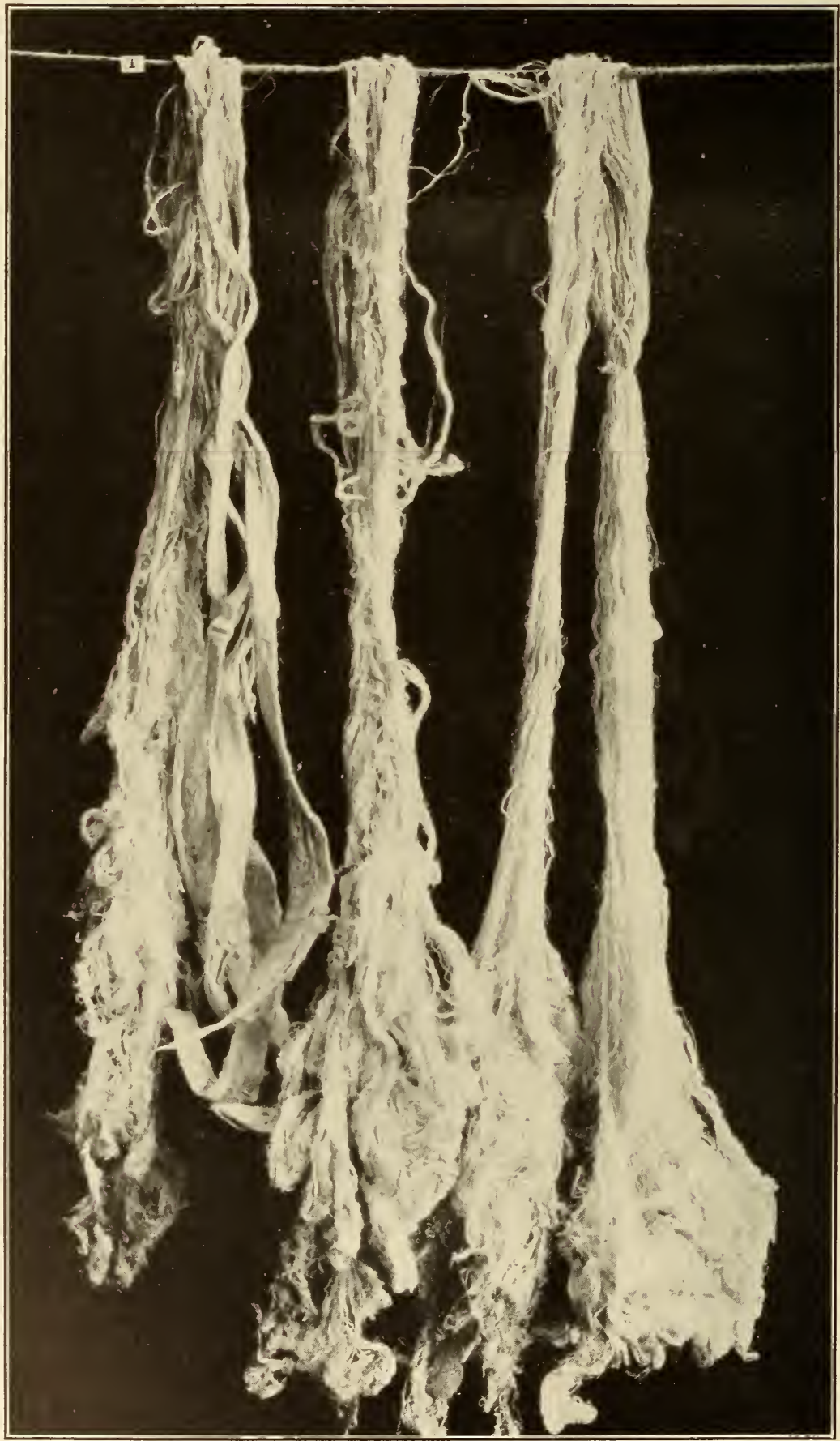

FIG. 9.-Shanghai frisons (raw) used in spun-silk manufacture 


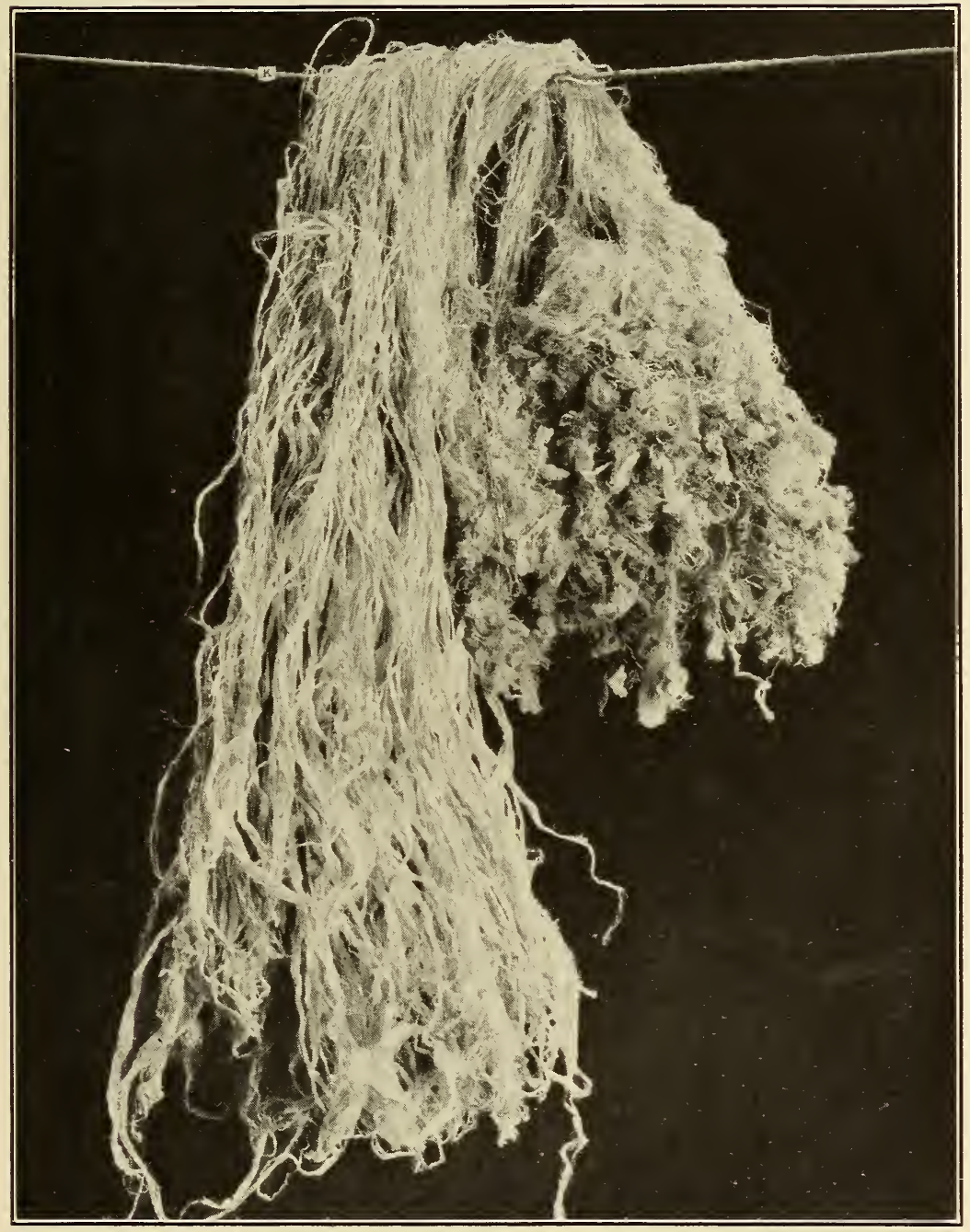

Fig. Io.-Italian classical yellow frisons (raw) used in spun-silk manufacture 


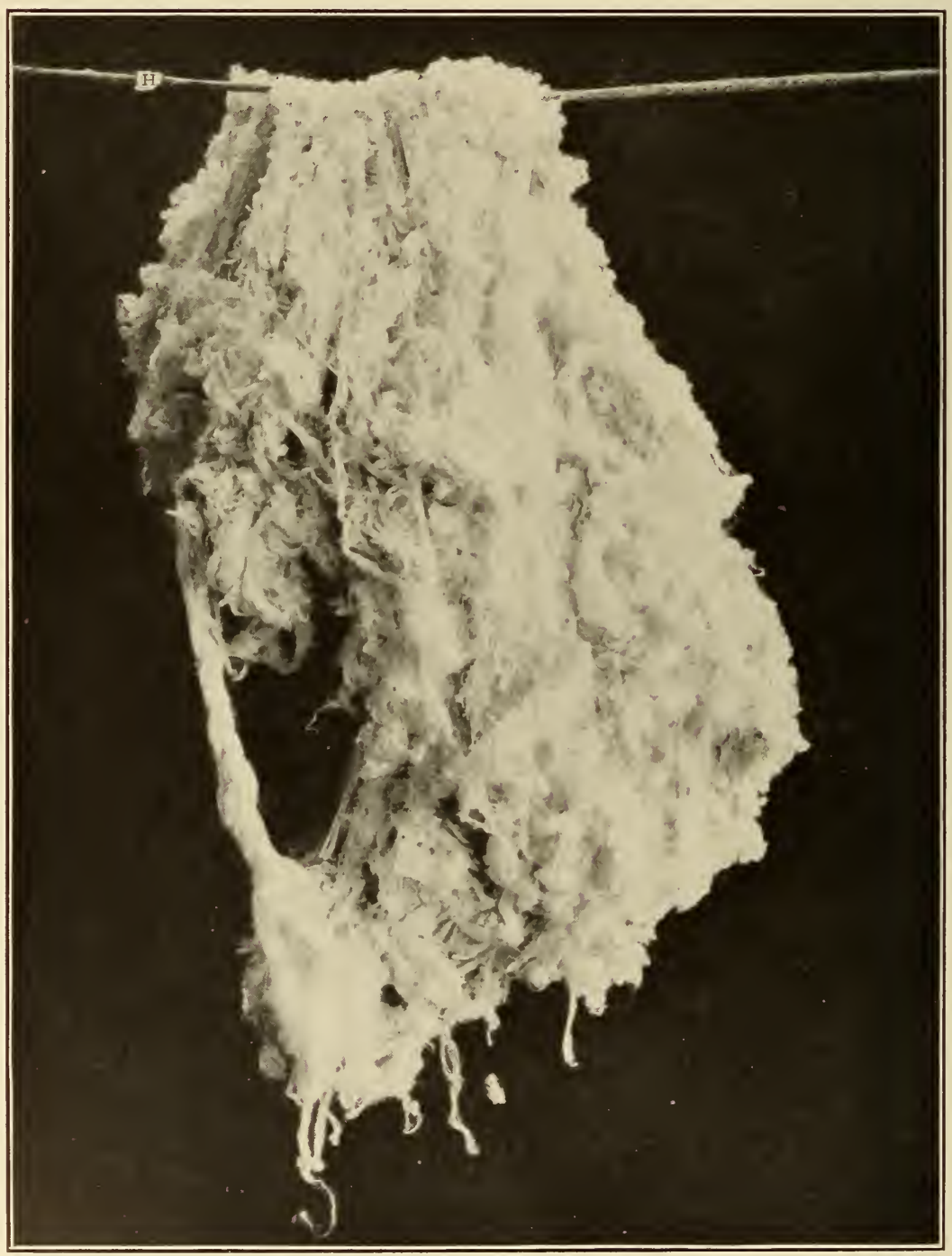

FIG. II.-Italian classical yellow frisons (boiled off) used in spun-silk manufacture 

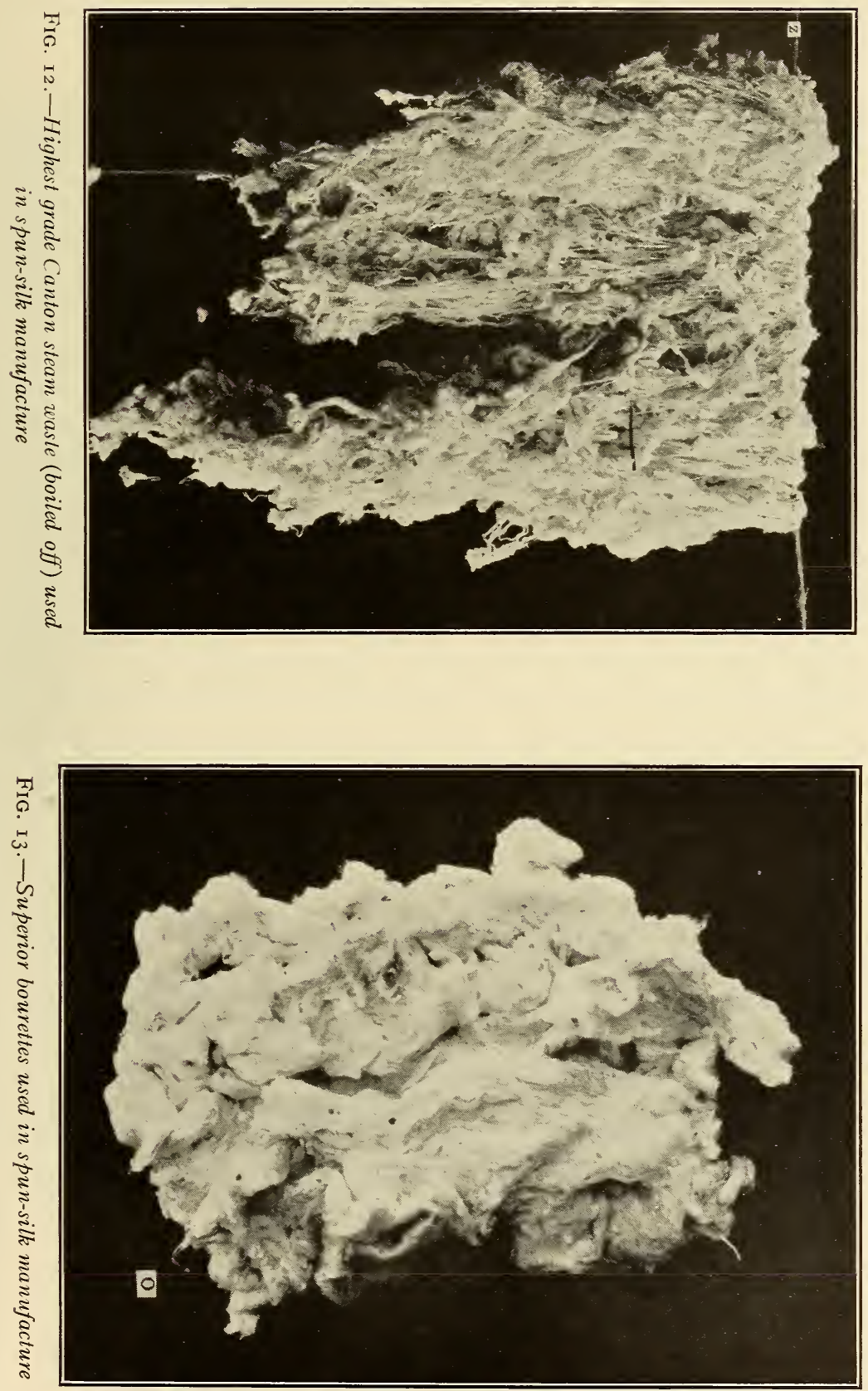


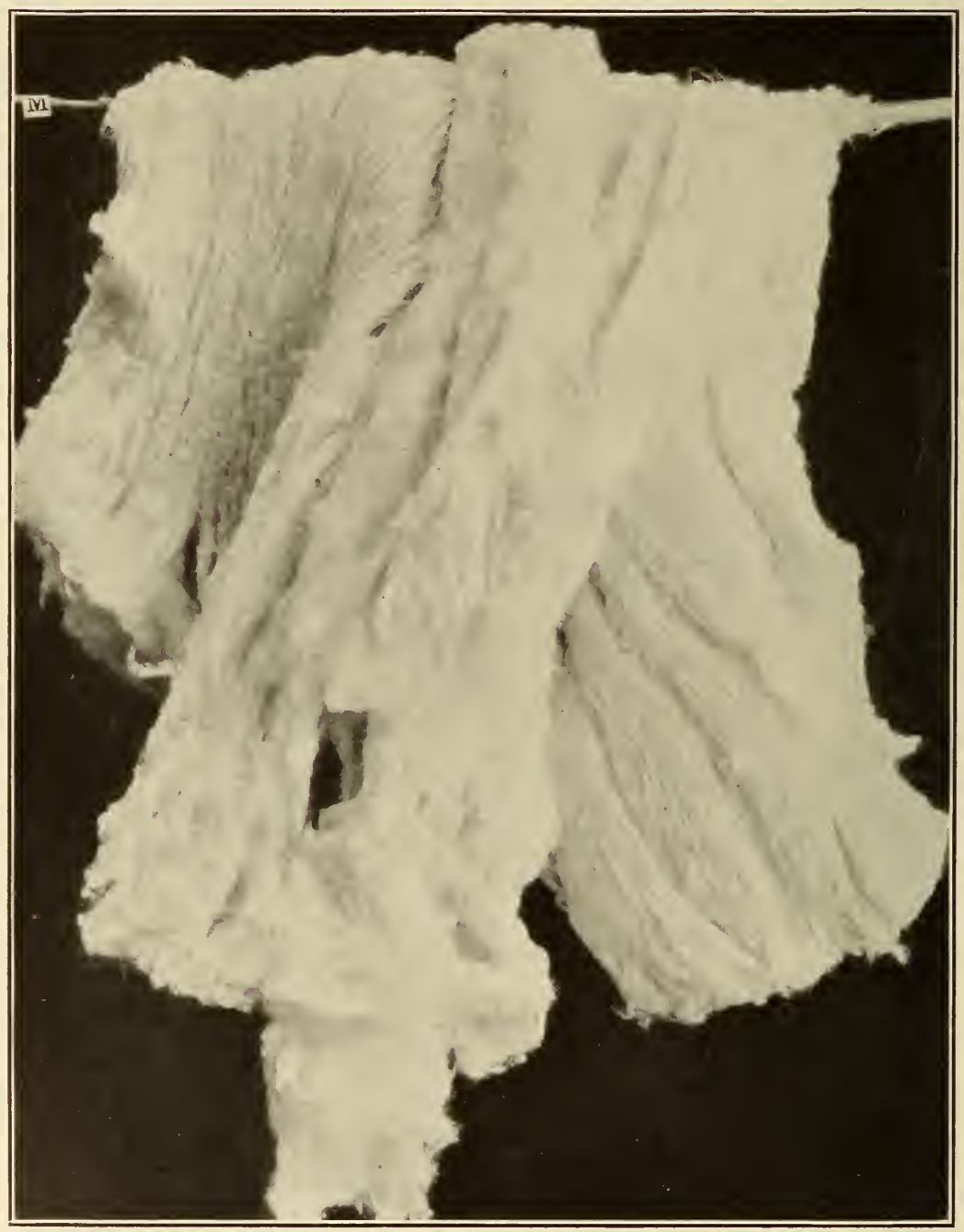

Fig. I4. - White noils produced from silk waste in the process of spun-silk manufacture 


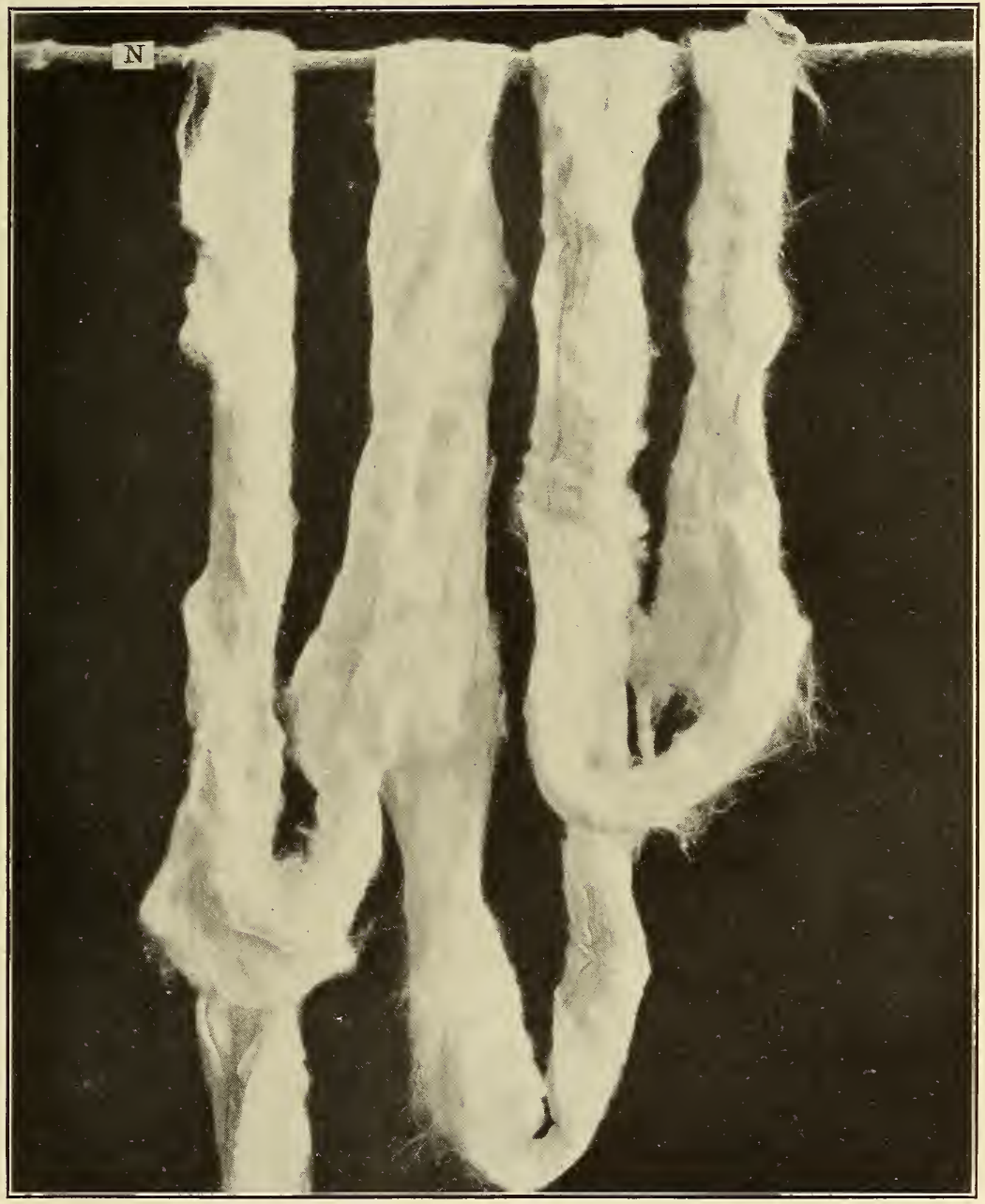

FIG. I5.-White combed silk produced from long noils in the process of spun-silk manufacture 


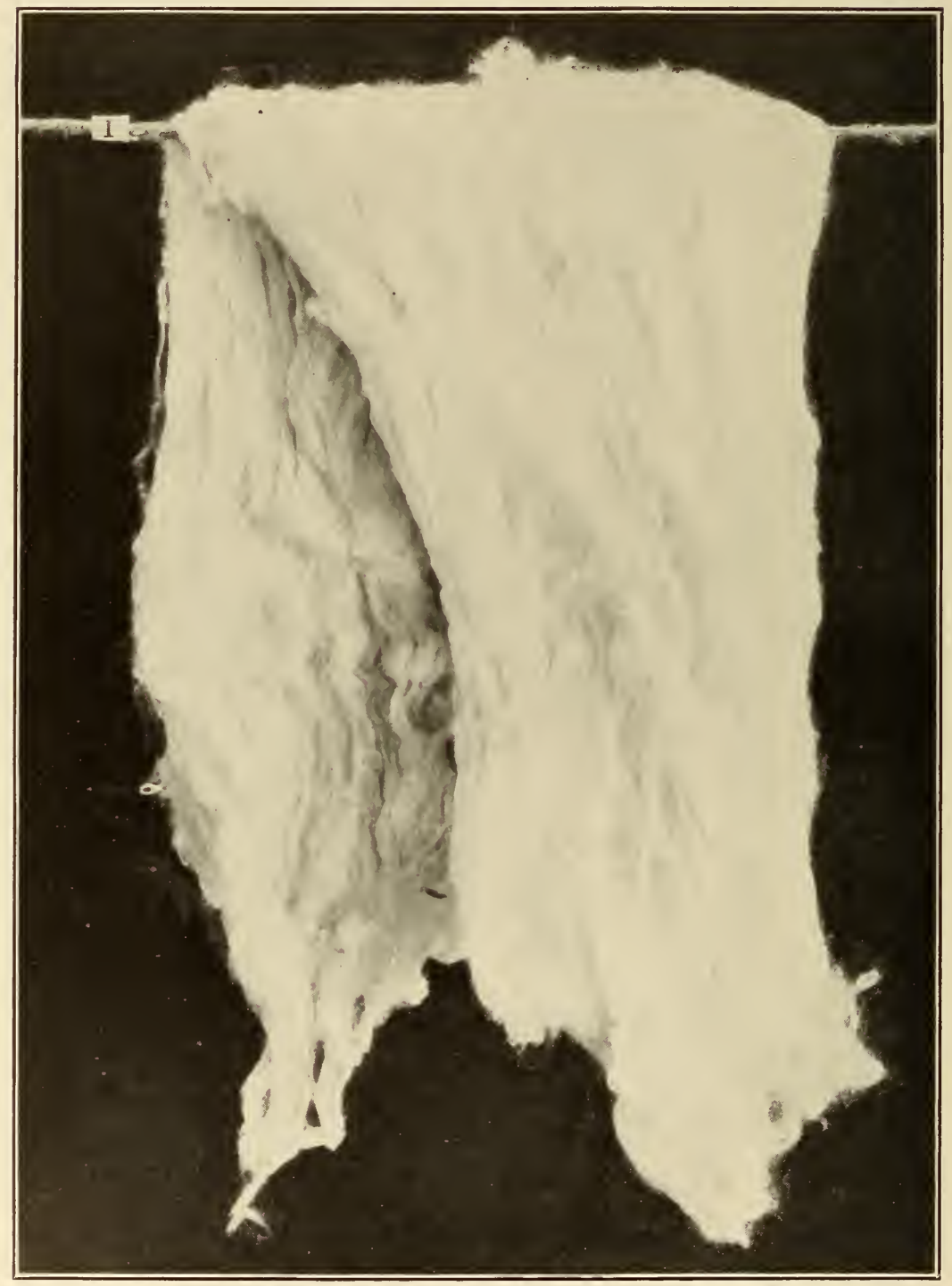

FIG. I6.-Lapped silk prepared in the process of spun-silk manufacture 
unsuitable for reeling. Figure 7 shows the pierced cocoons after the gum has been boiled off.

Figures 9, Io, and I I show two forms of frisons, Shanghai and Italian classical, raw and boiled off.

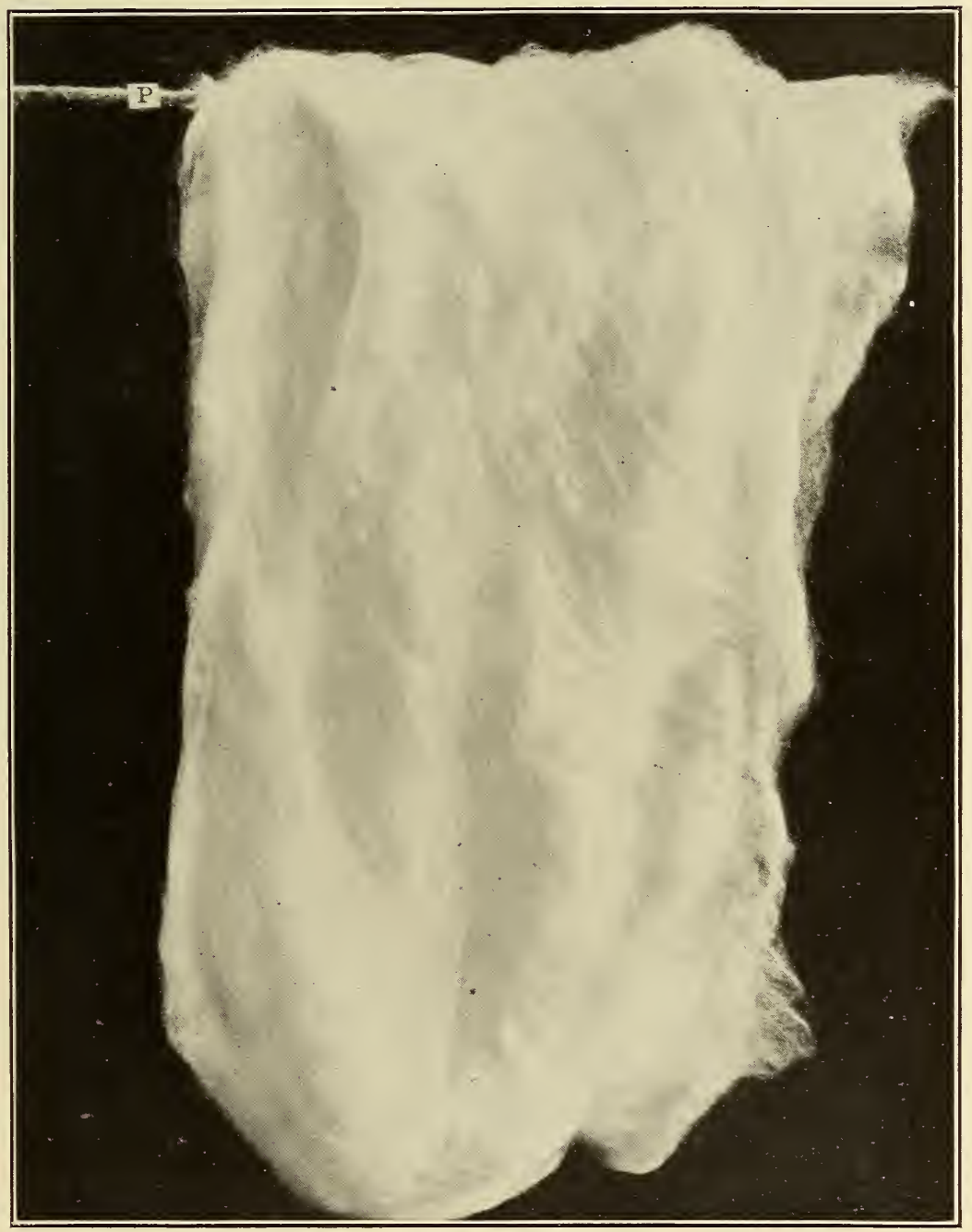

FIG. I7.-Dressed silk prepared in the process of spun-silk manufacture

A comparison of the raw and boiled-off conditions of Canton steam waste is shown by Figures 2 and 12 . This is a form of frison which is produced in Canton.

The bourettes, which is a waste obtained in the winding, throwing, or weaving processes of true silk, is shown in Figure I3. 
Figure I4 shows waste silk boiled off and further advanced in its manufacturing process. The product of the next process is shown in Figure 15, where the combed material is presented.

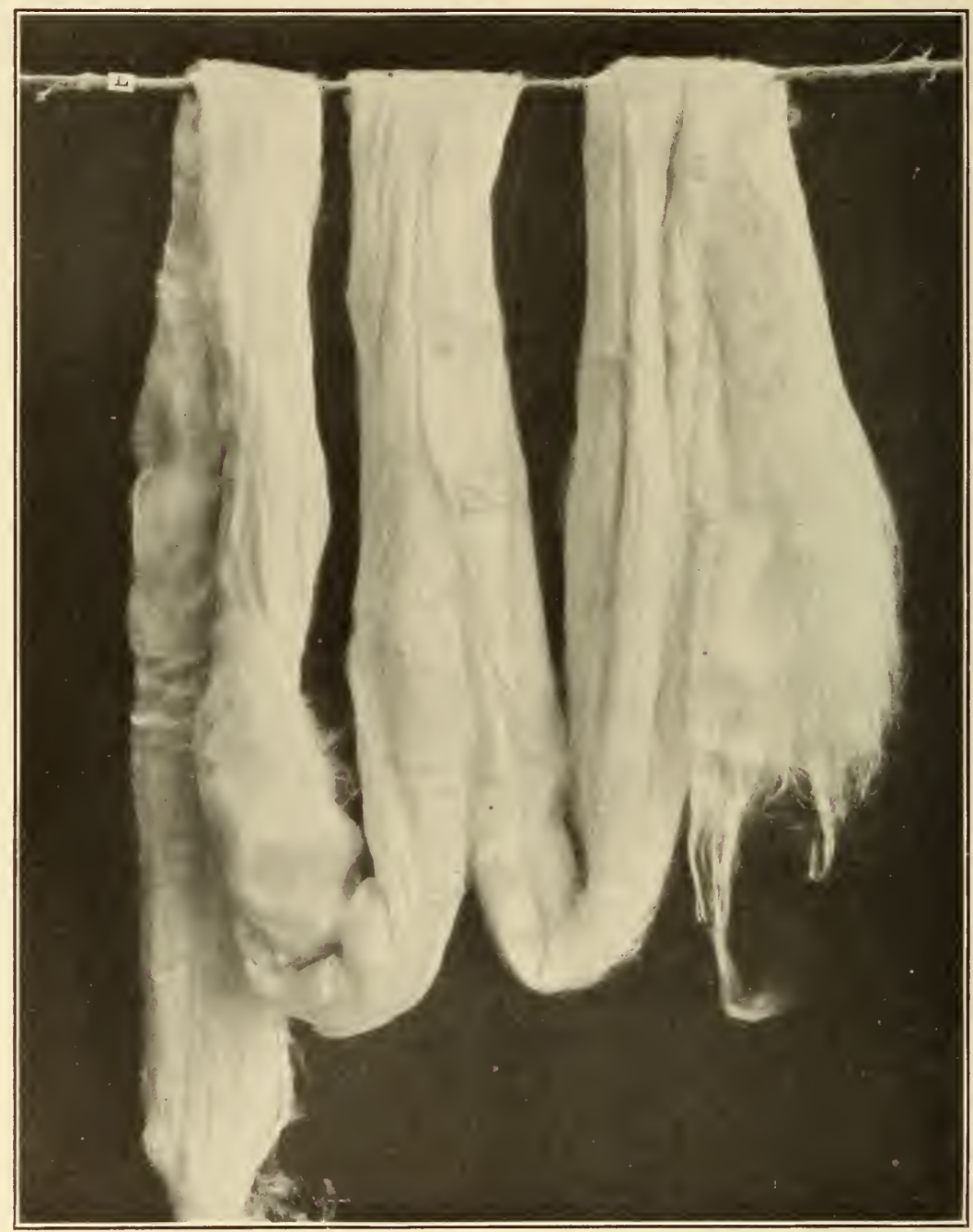

FIG. I8.-Spreader lap of dressed silk ready for preparing in the process of spun-silk manufacture

Figures I6, I7, and 18 show, respectively, the results of lapping, pressing, and spreading of waste silk prepared from any of the classes.

Washington, April 2, I 924. 